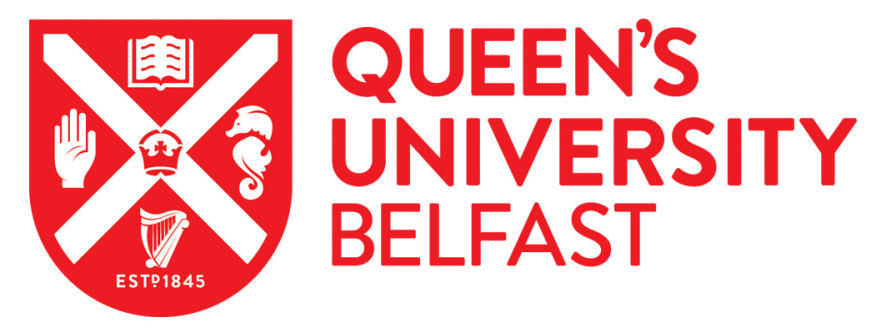

\title{
Statin Use and Reduced Risk of Biliary Tract Cancers in the United Kingdom Clinical Practice Research Datalink
}

Liu, Z., Alsaggaf, R., McGlynn, K. A., Anderson, L. A., Tsai, H-T., Zhu, B., Zhu, Y., Mbulaiteye, S. M., Gadalla, S. M., \& Koshiol, J. (2019). Statin Use and Reduced Risk of Biliary Tract Cancers in the United Kingdom Clinical Practice Research Datalink. Gut, 68, 1458-1464. https://doi.org/10.1136/ gutjnl-2018-317504

\section{Published in:}

Gut

\section{Document Version:}

Peer reviewed version

Queen's University Belfast - Research Portal:

Link to publication record in Queen's University Belfast Research Portal

\section{Publisher rights}

(c) 2018 The Authors. This work is made available online in accordance with the publisher's policies. Please refer to any applicable terms of use of the publisher.

\section{General rights}

Copyright for the publications made accessible via the Queen's University Belfast Research Portal is retained by the author(s) and / or other copyright owners and it is a condition of accessing these publications that users recognise and abide by the legal requirements associated with these rights.

Take down policy

The Research Portal is Queen's institutional repository that provides access to Queen's research output. Every effort has been made to ensure that content in the Research Portal does not infringe any person's rights, or applicable UK laws. If you discover content in the Research Portal that you believe breaches copyright or violates any law, please contact openaccess@qub.ac.uk. 


\section{Statin Use and Reduced Risk of Biliary Tract Cancers in the United Kingdom Clinical Practice Research Datalink}

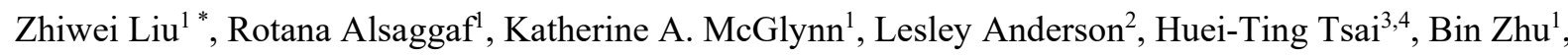
Yue Zhu ${ }^{5}$, Sam M. Mbulaiteye ${ }^{1}$, Shahinaz M. Gadalla ${ }^{1}$, Jill Koshiol ${ }^{1}$

Short title: Statin Use and Risk of Biliary Tract Cancers

\section{Author Affiliations:}

1. Division of Cancer Epidemiology and Genetics, National Cancer Institute, Bethesda, Maryland, USA

2. Centre for Public Health, School of Medicine, Dentistry and Biomedical Science, Queen’s University Belfast, United Kingdom

3. Office of Surveillance and Epidemiology, Center for Drug Evaluation and Research, U.S. Food and Drug Administration, Silver Spring, Maryland, USA

4. Lombardi Comprehensive Cancer Center, Georgetown University Medical Center, Georgetown University, Washington D.C., USA

5. Department of Epidemiology \& Biostatistics, Milken Institute School of Public Health, The George Washington University, Washington DC, USA

\section{Corresponding author:}

Zhiwei Liu, Ph.D., Division of Cancer Epidemiology and Genetics, National Cancer Institute, 9609 Medical Center Drive, Bethesda, MD 20850. Phone: 240-276-6726; Fax: 240-276-7806, email address: zhiwei.liu@,nih.gov 
Conflicts of Interest: The fifth author, Dr. Tsai, is currently an employee of the US Food and Drug Administration. The views expressed in this article are those of the authors and not necessarily those of the Food and Drug Administration. Other authors have none to declare.

\title{
Author contributions to manuscript
}

ZL was involved in the study design, analysis and interpretation of the data, and writing the manuscript. RA, KAM, LA, HTT, YZ, SMM, and SMG were involved in conception of the study, interpretation of the data, and revision of the manuscript. BZ was involved in data analysis, interpretation of the data and revision of the manuscript. JK was involved in conception of the study, study design, interpretation of the data, and writing the manuscript. All authors revised the article critically for important intellectual content and gave final approval of the version to be published.

Funding: Intramural Research Program of the National Institutes of Health, National Cancer Institute, Division of Cancer Epidemiology and Genetics. The funders had no role in the conduct of this research.

\begin{abstract}
Abbreviations: AVC, ampulla of Vater cancer; BMI, body mass index; BTC, Biliary tract cancer; CI, confidence interval; CPRD, Clinical Practice Research Datalink; GBC, gallbladder cancer; Q, quartile; OR, odds ratios
\end{abstract}

Word count: 3319 


\begin{abstract}
Objective: To evaluate the association between statin use and risk of biliary tract cancers (BTCs).

Design: This is a nested case-control study based on the United Kingdom Clinical Practice Research Datalink (CPRD). We included cases diagnosed with incident primary BTCs, including cancers of the gallbladder, bile duct (i.e., both intrahepatic and extrahepatic cholangiocarcinoma), ampulla of Vater, and mixed type, between 1990 and 2017. For each case, we selected five controls who did not develop BTCs at the time of case diagnosis, matched by sex, year of birth, calendar time, and years of enrollment in the general practice using incidence density sampling. A history of prescribed medications 1 year prior to diagnosis/selection was obtained from the patient prescription records. Odds ratios (ORs) and 95\% confidence intervals (CIs) for associations between statins and BTC overall and by subtypes were estimated using conditional logistic regression, adjusted for relevant confounders.
\end{abstract}

Results: We included 3,118 BTC cases and 15,519 cancer-free controls. Current statin use versus non-use was associated with a reduced risk of all BTCs combined (adjusted $\mathrm{OR}=0.88$, 95\%CI: 0.79-0.98). The reduced risks were most pronounced among long-term users, as indicated by increasing number of prescriptions $\left(P_{\text {trend }}=0.016\right)$ and cumulative dose of statins $\left(P_{\text {trend }}=0.008\right)$. The magnitude of association was similar for statin use and risk of individual types of BTCs. The reduced risk of BTCs associated with current statin use versus non-use was more pronounced among persons with diabetes (adjusted $\mathrm{OR}=0.72,95 \% \mathrm{CI}$ : 0.57-0.91). Among non-diabetics, the adjusted OR for current statin use versus non-use was 0.91 (95\%CI: 0.81-1.03, Pheterogeneity $=0.007)$. 
Conclusion: We provide evidence that current, but not former, statin use was associated with a lower risk of BTCs compared with nonuse of statins. If replicated, particularly in countries with a high incidence of BTCs, our findings could pave the way for evaluating the value of statins for BTC chemoprevention.

Key words: ampulla of Vater cancer, biliary tract cancer, cholangiocarcinoma, CPRD, gallbladder cancer, statin

\section{Short summary}

1. What is already known about this subject?

- Statins are commonly used cholesterol-lowering medications that have demonstrated effectiveness in the primary and secondary prevention of cardiovascular disease.

- Several epidemiological studies have shown that statins are associated with a lower risk of gallstone disease (gallstones or a history of cholecystectomy), but associations with biliary tract cancers (BTCs) have not been well studied.

2. What are the new findings?

- There was significantly reduced risk of biliary tract cancers among current users of statins, as compared with non-users (odds ratio, 0.88).

- The reduced risks were most pronounced among long-term users, as indicated by increasing number of prescriptions $(P$ for trend $=0.016)$ and cumulative dose of statins $(P$ for trend $=0.008)$.

3. How might it impact on clinical practice in the foreseeable future?

- Current or long-term statin use may reduce risk of biliary tract cancers. 
- If replicated in other settings, the value of statins for BTC chemoprevention should be evaluated. 


\section{Introduction}

Biliary tract cancers (BTCs) are comprised of cancers of the gallbladder, bile duct (i.e., both intrahepatic and extrahepatic cholangiocarcinoma), and ampulla of Vater. BTCs are rare but highly fatal diseases, with a median overall survival of $\sim 12$ months.[1] Although the etiology of BTCs is largely unknown, the epidemiologic and molecular characteristics suggest that they are distinct disease entities.[1,2] For example, gallbladder cancer (GBC) is more common in women than men, while other BTCs are more common in men.[3] Similarly, cirrhosis and infection with hepatitis B and $\mathrm{C}$ viruses are associated with intrahepatic cholangiocarcinoma, while their associations with GBC and ampulla of Vater cancer (AVC) are less clear. $[1,4]$

Despite these differences, BTCs share common risk factors. For example, disorder of lipid regulation (i.e., hyperlipidemia) has been associated with an increased risk of cancer at all sites in the biliary tract.[5] Hyperlipidemia is thought to interact with inflammation and proinflammatory immune response to influence the risk of BTCs.[6, 7] For GBC, local inflammation due to gallstones plays a central role,[8] while for cholangiocarcinoma, both intrahepatic and extrahepatic sclerosing cholangitis play a major role.[1] Inflammation from biliary adenomas, which are seen in patients with familial adenomatous polyposis,[9] is thought to contribute to the 100-fold higher risk of AVC in that population.[10] Finally, other causes of inflammation, such as bacterial infection and obesity/metabolic syndrome, may play a role in the etiology of BTC.[1]

Given these strong ties with dyslipidemia and inflammation, statins (3-hydroxy-3methylglutaryl coenzyme A [HMG-CoA] reductase inhibitors) could potentially reduce the risk 
of BTCs. Statins are commonly used cholesterol-lowering medications that have demonstrated effectiveness in the primary and secondary prevention of cardiovascular disease.[11] Several studies have shown that statins are associated with a lower risk of gallstone disease (gallstones or a history of cholecystectomy) $[12,13,14,15]$, but associations with BTCs have not been well studied. To further our understanding of the associations between statins and BTCs, we thus conducted a nested case-control study within a large database of primary care electronic medical records - the United Kingdom (UK) Clinical Practice Research Datalink (CPRD).[16]

\section{Methods}

This study is based on data from the CPRD obtained under license from the UK Medicines and Healthcare products Regulatory Agency. The data are provided by patients and collected by the national health service (NHS) as part of their care and support. The interpretation and conclusions contained in this study are those of the authors alone. The study was approved by the Independent Scientific Advisory Committee of the CPRD (proposal\#17_160.R).

\section{Study Population and Design}

The UK CPRD was established in 1987 and contains information on $~ 8.5 \%$ (13.3 million) of the UK population. All data are provided by general practitioners; the CPRD population is representative of the general UK population.[17] Detailed information includes demographic data, physician contacts, tests conducted, and medications prescribed. Diagnoses, physical findings, symptoms, and administrative events, such as referrals to specialists, are recorded using Read codes, the standard clinical terminology system used in general practice in the UK.[18] 
In this nested case-control study, we included all persons whose most recent active registration at a CPRD practice overlapped with the study period from 1990 (three years after the establishment of the database) through 2017. Entry date was defined as the patient's current registration date (i.e., the later of the practice's up-to-standard date), and exit date was defined as the date of cancer diagnosis/selection, death, leaving the practice, or last collection of data from the practices, whichever occurred first. Eligible cases included persons aged 21-100 years with a first cancer diagnosis (except non-melanoma skin cancer) of BTC (Read codes provided in Supplementary Table 1) identified in CPRD during 1990-2017. To ascertain statin use, we excluded the 1-year period prior to cancer diagnosis to minimize the possibility of reverse causation (i.e., incipient cancer leading to statin use); therefore, the index date was defined as the date of BTC diagnosis minus one year. All cases were required to have at least one year of recorded activity in the CPRD prior to the index date (i.e., two years total of enrollment were required).

Five controls per case were randomly selected using incidence density sampling. Controls were individually matched on sex, year of birth ( $+/-3$ years), index year $(+/-3$ years), and number of years in the general practice and in the CPRD prior to index date. All controls were required to be alive and cancer-free (except for non-melanoma skin cancer) prior to the diagnosis date of the matched case and were required to have at least one year of enrollment in the CPRD participating practice prior to the case index date (i.e., the date of BTC diagnosis minus one year; thus, two years total of enrollment were required). Selected controls with exit date before entry were excluded $(\mathrm{N}=55)$.

Ascertainment of Statins and Covariates 
A history of prescribed medications prior to the index date was obtained from the patient prescription records. Drugs of interest included statins, other lipid-lowering agents (i.e., bile acid sequestrant, cholesterol absorption inhibitor, fibrate, nicotinic acid derivative, Omega-3 fatty acid, and Bis-phenol antioxidant), treatment for type 2 diabetes (i.e., metformin, insulin, Acetohexamide, Tolbutamide, Chlorpropamide, Glibenclamide, Glibornuride, Gliclazide, Rosiglitazone, Tolazamide, and Tolbutamide), aspirin, and cortisone, which were included because of their potential effect on metabolism. Statin use was defined as having two or more statin prescriptions recorded, and nonuse of statins was defined as having 0-1 prescriptions.[19] Former statin use was defined as use ending more than one year prior to the index date. Use ending within one year prior to the index date was considered as current use. Based on the distribution among controls, statin use was classified by time since first recorded statin use (0-2, $3-5,6-8$, and $9+$ years $)$, number of prescriptions $(2-15,16-35,36-65$, and $66+$, representing approximate duration of use) and cumulative dose (quartiles), which was defined as number of pills multiplied by the dose per pill. This grouping strategy permitted examination of the trend for the association of increasing statin use with risk for BTCs. Finally, specific commonly used statins (atorvastatin, simvastatin, pravastatin, and rosuvastatin) were examined individually.

Because body mass index (BMI), smoking, alcohol drinking, diabetes mellitus, gallstones, cirrhosis, hepatitis virus infection, chronic heart disease, and dyslipidemia may be associated with both statin use and BTCs or BTCs at specific subsites, we identified persons who had these conditions prior to the index date. We also assessed healthy user effect, healthy adherer effect, and functional status prior to the index date because these factors have been suggested as important confounders in observational studies (Supplementary Materials).[20]

\section{Statistical analyses}


We used conditional logistic regression to estimate odds ratios (ORs) for the association of statins with BTCs overall and with individual types (i.e., GBC, cholangiocarcinoma, and AVC). The regression model included adjustment for known BTC risk factors: BMI, smoking status, alcohol drinking status, and a history of diabetes.[21] GBC-specific analyses excluded 177 controls with a history of cholecystectomy because those controls were not at risk for developing GBC, and history of gallstones was additionally included in the model. Cholangiocarcinoma-specific analyses additionally included history of cirrhosis in the model.

Other potential confounders were selected if they changed the adjusted OR for BTC and statin use status by more than $10 \%$. We first considered a fully adjusted model that included all potential confounders: a history of hepatitis virus infection, chronic heart disease, dyslipidemia, high exercise, healthy diet, cancer screening, influenza vaccination, pneumonia, dementia, comorbidity, and use of treatment for type 2 diabetes, aspirin, cortisone, or other lipid-lowering agents. However, additional adjustment for those variables resulted in only marginal changes in the ORs (Supplementary Table 2); such adjustments were therefore not included in the final model. We also selected covariates by mutually entering all potential confounders into a stepwise logistic regression model, with $P<0.15$ as the model entry criterion and $P<0.05$ for a variable to remain in the model. Likewise, adjustment for variables selected resulted in OR changes of less than $10 \%$ (Supplementary Table 2). We thus only present results from the minimally adjusted model. We tested for linear trends across statin use categories with the Wald test using categorical values of the number of prescriptions and cumulative dose with 1 degree of freedom.

We evaluated potential effect modification by matching variables (i.e., sex, age at index date $[\leq 70$ versus $>70$ years; the age cutoff was chosen to create two equally large age groups 
among the control subjects, among whom the median age was 72 years], and index year $[\leq 2004$ versus $>2004$ because $10 \mathrm{mg}$ of simvastatin became available over-the-counter in August 2004] [22]). Likelihood ratio tests were used to compare models with and without an interaction term between statin use and each potential modifier. Because statin use has been associated with increased risk of diabetes, $[23,24,25]$ we conducted a joint analysis of diabetes and statin use initiated before or after diabetes diagnosis. We used patients with diabetes who did not use statins as the reference group for a model focused on the potential protective effect of statins on BTCs among patients with diabetes; this model was additionally adjusted for treatment for type 2 diabetes. We then reran the model using non-diabetic patients who did not use statins as the reference group to focus on the effect of former or current statin use among non-diabetics.

In sensitivity analyses, we focused on incident statin users (defined as those with the first recorded use of statins of $\geq 5$ years after entry into CPRD) to limit the effect of confounding (i.e., intended and unintended treatment effects) and yield results closer to those that would be seen in randomized clinical controlled trial.[26] We also conducted analyses excluding 145 cases with carcinoma in situ of the biliary system and their matched controls, excluding subjects with nonbiliary cancer in situ (i.e., all carcinoma in situ except that of the biliary system) since diagnosis of in situ cancer may have led to lifestyle changes, or excluding subjects with missing/unknown information on smoking, alcohol drinking, and BMI. Finally, although information on treatment is not complete in the CPRD because this information is reported by primary care physicians only, not specialists, cases with supporting clinical codes that indicated presence of BTCs such as diagnostic exams (biopsies), treatment (chemotherapy, radiotherapy, surgery), palliative care, and referrals to specialty care were considered as confirmed BTCs. 
Statistical analyses were performed using R Statistical Software (Foundation for Statistical Computing, Vienna, Austria). All statistical tests were 2-sided, and $P<0.05$ was considered statistically significant.

\section{Results}

Table 1 shows the distribution of demographic characteristics and other potential risk factors. A total of 3,118 BTC cases (708 GBC, 1678 cholangiocarcinoma, 228 AVC, 500 mixed, 4 unknown) and 15,519 cancer-free controls were included (Table 1). By design, cases and controls were individually-matched on sex, age, index year, and years in the CPRD participating practice prior to the index date. Cases were more likely to be obese; be current smokers; drink alcohol; have a history of chronic diseases, including diabetes, gallstones, and cirrhosis; be infected with hepatitis viruses; have treatment for type 2 diabetes; and use aspirin or cortisone. Controls were more likely to be diagnosed with dementia.

Table 2 shows adjusted ORs for statin use and risk of all BTCs combined. Although former statin use was not associated with BTC risk, current use versus non-use was associated with a reduced risk of BTCs (adjusted $\mathrm{OR}=0.88,95 \% \mathrm{CI}$ : 0.79-0.98, Table 2). Individuals who started using statins nine or more years before the index date had reduced risk of BTCs $(\mathrm{OR}=0.85,95 \% \mathrm{CI}: 0.72-1.01)$, but the trend was not consistent across increasing categories of time since first statin use $\left(P_{\text {trend }}=0.128\right)$. Although there was some evidence of a dose-response trend with increasing number of prescriptions (Ptrend=0.016) and cumulative dose of statins (Ptrend $=0.008$ ), the trend was not consistent across all categories, and only the highest quartile (Q4) compared with nonuse of statins was statistically significant. For example, compared with nonuse of statins, the adjusted OR of the highest quartile (Q4) for cumulative dose was 0.81 
(95\%CI: 0.68-0.96). We did not observe heterogeneity by type of statin but had limited statistical power for individual types of statins (Supplementary Table 3).

The reduced risk associated with statin use was similar for individual types of BTCs (Table 3). For example, the adjusted ORs for current statin use versus nonuse and risk of GBC, cholangiocarcinoma, and AVC were 0.86 (95\%CI: 0.67-1.09), 0.87 (0.75-1.01), and 0.89 (0.591.34), respectively. There were no clear dose-response relationships between risk of individual types of BTCs and number of prescriptions and cumulative dose, but the ORs were of similar magnitude to those for BTCs overall.

The observed associations were similar for men and women, for individuals $\leq 70$ and $>70$ years of age at index date, and for those with an index year of $\leq 2004$ and $>2004$ (all $P_{\text {heterogeneity }}>0.05$, Supplementary Table 4 ). In the joint analysis by history of diabetes, we found that statin use was associated with a lower risk of BTCs among patients with diabetes, with an adjusted OR for current statin use versus non-use of 0.72 (95\% CI: 0.57-0.91). Among non-diabetics, the adjusted OR for current statin use versus non-use was 0.91 (95\% CI: 0.81-1.03. $\left.P_{\text {heterogeneity }}=0.007\right)$. The reduced risk of BTCs was more pronounced among participants with statins prescribed before diabetes was diagnosed (adjusted $\mathrm{OR}=0.59,95 \% \mathrm{CI}: 0.44-0.81$ ) than among those with statins prescribed after diabetes was diagnosed (0.84 [0.66-1.08], $\left.P_{\text {heterogeneity }}=0.03\right)$.

In sensitivity analyses, the adjusted ORs remained stable in patients with incident current statin use $(\mathrm{OR}=0.81,95 \% \mathrm{CI}: 0.70-0.94)$, excluding persons with biliary carcinoma in situ and their controls (OR for current statin use $=0.88,95 \% \mathrm{CI}$ : 0.79-0.98), and among cases and controls without a history of cancer in situ except carcinoma in situ of biliary system $(0.89,95 \% \mathrm{CI}$ : 0.79 - 
0.99) or without missing/unknown status for smoking, alcohol drinking, and BMI $(0.90,95 \% \mathrm{CI}$ : 0.80-1.02).

\section{Discussion}

In this large study, we observed a reduced risk of BTCs among current statin users compared to nonusers. Reduced risk of BTCs was also more pronounced among subjects with the highest number of prescriptions and cumulative dose of statins, suggesting that long-term statin users may have a lower risk of developing BTCs. The risk estimate was consistent across individual types of BTCs, age groups, sex, and calendar time. Adjustment for various risk factors did not substantively alter the results. Finally, we also observed a risk reduction among persons with diabetes. If replicated in other studies, these findings suggest that statins may have a role as chemopreventive agents.

\section{Comparison to other studies}

To our knowledge, this study is the first to address the association between statin use and risk of cancer across the biliary tract. Our findings are in line with the one previous study focusing on one individual type of BTC (cholangiocarcinoma) in Taiwan, which reported that the adjusted OR for statin use versus nonuse for cholangiocarcinoma was 0.80 (95\%CI: 0.71 0.90).[27] The results are also consistent with studies that have demonstrated a decreased risk of gallstone disease,[12, 13, 14, 15] a risk factor for BTCs,[28] especially GBC.[1,2] Statins could potentially reduce risk of BTCs through suppression of biliary cholesterol secretion and saturation and anti-inflammatory and endothelial effects.[29, 30] The reduction in hepatic and gallbladder bile cholesterol concentrations could alter bile acid composition and interfere with gallstone production or even promote gallstone dissolution.[31] In addition, both experimental 
and clinical studies provide evidence that statins have anti-inflammatory effects.[29, 30] Statins reduce circulating $\mathrm{C}$-reactive protein and pro-inflammatory cytokines and chemokines. $[32,33]$ Statins also favorably affect important pathways regulating nitric oxide bioavailability, which is critical for maintaining endothelium homeostasis via statins' vasodilatory, anti-inflammatory, and overall anti-atherogenic effects. In addition, statins have been shown to regulate expression of many inflammatory genes.[30] Associations between statin use and lower risk of cancers related to inflammation, including cancers of the colorectum $[34,35]$ and esophagus $[36,37,38]$, have been reported in epidemiological studies. However, we did not observe a joint effect of use of both statins and aspirin (data not shown), as has been reported for cancer of the esophagus $[37,38]$.

Our findings of reduced BTC risk among persons with diabetes using statins should be interpreted with caution. Some studies suggest that statins may increase the risk of diabetes, although results are inconsistent.[23, 24] Experimental data support the hypothesis that statins may cause diabetes by altering glucose homeostasis through both impaired insulin secretion and diminished insulin sensitivity.[39] Following this hypothesis, statins could increase the risk of BTCs by increasing risk of diabetes. However, in the present study, we observed a reduced risk of BTCs among persons with diabetes who used statins before their diabetes was diagnosed, as compared with those with diabetes who did not use statins. Lipophilic (simvastatin and atorvastatin) and hydrophilic (pravastatin and rosuvastatin) statins have been observed to have different diabetogenic effects,[40] but we lacked the power to investigate whether the observed reduced risk of BTCs was driven by specific types of statins. Additional studies are needed to clarify the associations between statins, diabetes, and BTCs, but overall our results suggest that statins reduce the risk of BTCs both in patients with diabetes and those without. 
Our study has several strengths. First, it was conducted using a large, well-established, validated, longitudinal primary-care database with long-term follow-up. This database is known for accuracy of diagnoses, including cancer, and completeness of pharmacy data.[41, 42] Second, all information on diseases and drug exposures in the CPRD is recorded prior to BTC diagnosis and in the absence of a study hypothesis, reducing the risk of recall bias. Third, we could evaluate the impact of various important confounders (BMI, smoking, alcohol drinking, a history of diabetes, hepatitis virus infection, chronic heart disease, dyslipidemia, and use of treatment for type 2 diabetes, aspirin, cortisone, or other lipid-lowering agents); such information is usually not accessible in registry-based studies. Although we did not adjust for socioeconomic status (SES), SES has been not associated with statin prescribing in England.[43] In addition, cases and controls were matched on general practice, and the universal health care coverage in the UK may, to some degree, control for SES. Finally, we conducted a large number of sensitivity analyses that further support the robustness of our findings.

Our study has a few limitations. First, although our sample size was sufficient for all BTCs combined, power was limited for individual types of BTCs and individual statins. Second, compliance rates among persons taking statins could not be evaluated, leading to potential exposure misclassification. Third, although we adjusted for several factors, these conditions could be incompletely captured in the database; residual confounding is possible even after our adjustment. For example, our adjustment for confounding by healthy user effect, healthy adherer effect, and functional status or cognitive impairment, which are not usually considered in observational studies,[20] did not change the magnitude of the association between statin use and risk of BTCs. Fourth, although previous validation studies have reported that cancer diagnoses are accurate and complete, $[41,44]$ the diagnosis of BTCs in the present study was not verified 
and misclassification cannot be ruled out. Further studies conducted in databases with validated cancer diagnosis are warranted. Fifth, use of statins may not be completely captured after 2004 because $10 \mathrm{mg}$ simvastatin became available over-the-counter at that time, and a previous study showed a decreased trend in statin prescribing since 2004.[22] We conducted a stratified analysis by calendar year but did not observe significant heterogeneity in the association before and after 2004. It is also likely that this misclassification occurs equally for cases and controls and thus is nondifferential by case-control status. If true, this misclassification could underestimate the strength of the reduced risk of BTCs associated with use of statins. Finally, we cannot rule out a potential role of chance given the number of tests evaluated with the potential for false positives.

In conclusion, this large observational study provides evidence that current or long-term statin use is associated with decreased risk of BTCs. Our findings should be replicated in other populations, particularly in high-risk areas, such as Chile, to confirm our observations and further establish the potential value of statins for BTC chemoprevention.

\section{Reference}

1 Valle JW, Lamarca A, Goyal L, Barriuso J, Zhu AX. New Horizons for Precision Medicine in Biliary Tract Cancers. Cancer Discov 2017;7:943-62.

2 de Groen PC, Gores GJ, LaRusso NF, Gunderson LL, Nagorney DM. Biliary tract cancers. N Engl J Med 1999;341:1368-78.

3 Randi G, Malvezzi M, Levi F, Ferlay J, Negri E, Franceschi S, et al. Epidemiology of biliary tract cancers: an update. Ann Oncol 2009;20:146-59.

4 Parag $M$, Engels EA, Koshiol J. Hepatitis B virus infection and the risk of cancer in the elderly US population. Int J Cancer 2018.

5 Andreotti G, Chen J, Gao YT, Rashid A, Chang SC, Shen MC, et al. Serum lipid levels and the risk of biliary tract cancers and biliary stones: A population-based study in China. Int J Cancer 2008;122:2322-9.

6 Espinoza JA, Bizama C, Garcia P, Ferreccio C, Javle M, Miquel JF, et al. The inflammatory inception of gallbladder cancer. Biochim Biophys Acta 2016;1865:245-54.

7 Koshiol J, Ferreccio C, Devesa SS, Roa JC, Fraumeni JF J. Biliary Tract Cancer. Cancer Epidemiology and Prevention 2017. 
8 Nogueira L, Freedman ND, Engels EA, Warren JL, Castro F, Koshiol J. Gallstones, cholecystectomy, and risk of digestive system cancers. Am J Epidemiol 2014;179:731-9.

9 Sanabria JR, Croxford R, Berk TC, Cohen Z, Bapat BV, Gallinger S. Familial segregation in the occurrence and severity of periampullary neoplasms in familial adenomatous polyposis. Am J Surg 1996;171:136-40; discussion 40-1.

10 Offerhaus GJ, Giardiello FM, Krush AJ, Booker SV, Tersmette AC, Kelley NC, et al. The risk of upper gastrointestinal cancer in familial adenomatous polyposis. Gastroenterology 1992;102:1980-2.

11 Cholesterol Treatment Trialists C, Baigent C, Blackwell L, Emberson J, Holland LE, Reith C, et al. Efficacy and safety of more intensive lowering of LDL cholesterol: a meta-analysis of data from 170,000 participants in 26 randomised trials. Lancet 2010;376:1670-81.

12 Suuronen S, Niskanen L, Paajanen P, Paajanen H. Declining cholecystectomy rate during the era of statin use in Finland: a population-based cohort study between 1995 and 2009. Scand J Surg 2013;102:158-63.

13 Erichsen R, Froslev T, Lash TL, Pedersen L, Sorensen HT. Long-term statin use and the risk of gallstone disease: A population-based case-control study. Am J Epidemiol 2011;173:162-70.

14 Tsai CJ, Leitzmann MF, Willett WC, Giovannucci EL. Statin use and the risk of cholecystectomy in women. Gastroenterology 2009;136:1593-600.

15 Bodmer M, Brauchli YB, Krahenbuhl S, Jick SS, Meier CR. Statin use and risk of gallstone disease followed by cholecystectomy. JAMA 2009;302:2001-7.

16 Herrett E, Gallagher AM, Bhaskaran K, Forbes H, Mathur R, van Staa T, et al. Data Resource Profile: Clinical Practice Research Datalink (CPRD). Int J Epidemiol 2015;44:827-36.

17 Lawson DH, Sherman V, Hollowell J. The General Practice Research Database. Scientific and Ethical Advisory Group. QJM 1998;91:445-52.

18 O'Neil M, Payne C, Read J. Read Codes Version 3: a user led terminology. Methods Inf Med 1995;34:187-92.

19 McGlynn KA, Hagberg K, Chen J, Graubard BI, London WT, Jick S, et al. Statin use and risk of primary liver cancer in the Clinical Practice Research Datalink. J Natl Cancer Inst 2015;107.

20 Shrank WH, Patrick AR, Brookhart MA. Healthy user and related biases in observational studies of preventive interventions: a primer for physicians. J Gen Intern Med 2011;26:546-50.

21 Ren HB, YU T, Liu C, Li YQ. Diabetes mellitus and increased risk of biliary tract cancer: systematic review and meta-analysis. Cancer Causes Control 2011;22:837-47.

22 Filion KB, Delaney JA, Brophy JM, Ernst P, Suissa S. The impact of over-the-counter simvastatin on the number of statin prescriptions in the United Kingdom: a view from the General Practice Research Database. Pharmacoepidemiol Drug Saf 2007;16:1-4.

23 Preiss D, Seshasai SR, Welsh P, Murphy SA, Ho JE, Waters DD, et al. Risk of incident diabetes with intensive-dose compared with moderate-dose statin therapy: a meta-analysis. JAMA 2011;305:2556-64.

24 Sattar N, Preiss D, Murray HM, Welsh P, Buckley BM, de Craen AJ, et al. Statins and risk of incident diabetes: a collaborative meta-analysis of randomised statin trials. Lancet 2010;375:735-42.

25 Ridker PM, Danielson E, Fonseca FA, Genest J, Gotto AM, Jr., Kastelein JJ, et al. Rosuvastatin to prevent vascular events in men and women with elevated C-reactive protein. $\mathrm{N}$ Engl J Med 2008;359:2195-207.

26 Schneeweiss S, Patrick AR, Sturmer T, Brookhart MA, Avorn J, Maclure M, et al. Increasing levels of restriction in pharmacoepidemiologic database studies of elderly and comparison with randomized trial results. Med Care 2007;45:S131-42.

27 Peng YC, Lin CL, Hsu WY, Chang CS, Yeh HZ, Tung CF, et al. Statins are associated with a reduced risk of cholangiocarcinoma: a population-based case-control study. Br J Clin Pharmacol 2015;80:755-61. 
28 Hsing AW, Gao YT, Han TQ, Rashid A, Sakoda LC, Wang BS, et al. Gallstones and the risk of biliary tract cancer: a population-based study in China. Br J Cancer 2007;97:1577-82.

29 Antonopoulos AS, Margaritis M, Lee R, Channon K, Antoniades C. Statins as anti-inflammatory agents in atherogenesis: molecular mechanisms and lessons from the recent clinical trials. Curr Pharm Des 2012;18:1519-30.

30 Jain MK, Ridker PM. Anti-inflammatory effects of statins: clinical evidence and basic mechanisms. Nat Rev Drug Discov 2005;4:977-87.

31 Tazuma S, Kajiyama G, Mizuno T, Yamashita G, Miura H, Kajihara T, et al. A combination therapy with simvastatin and ursodeoxycholic acid is more effective for cholesterol gallstone dissolution than is ursodeoxycholic acid monotherapy. J Clin Gastroenterol 1998;26:287-91.

32 Albert MA, Danielson E, Rifai N, Ridker PM, Investigators P. Effect of statin therapy on C-reactive protein levels: the pravastatin inflammation/CRP evaluation (PRINCE): a randomized trial and cohort study. JAMA 2001;286:64-70.

33 Rezaie-Majd A, Maca T, Bucek RA, Valent P, Muller MR, Husslein P, et al. Simvastatin reduces expression of cytokines interleukin-6, interleukin-8, and monocyte chemoattractant protein-1 in circulating monocytes from hypercholesterolemic patients. Arterioscler Thromb Vasc Biol 2002;22:11949.

34 Poynter JN, Gruber SB, Higgins PD, Almog R, Bonner JD, Rennert HS, et al. Statins and the risk of colorectal cancer. N Engl J Med 2005;352:2184-92.

35 Nguyen DM, Richardson P, El-Serag HB. Medications (NSAIDs, statins, proton pump inhibitors) and the risk of esophageal adenocarcinoma in patients with Barrett's esophagus. Gastroenterology 2010;138:2260-6.

36 Singh S, Singh AG, Singh PP, Murad MH, lyer PG. Statins are associated with reduced risk of esophageal cancer, particularly in patients with Barrett's esophagus: a systematic review and metaanalysis. Clin Gastroenterol Hepatol 2013;11:620-9.

37 Kastelein F, Spaander MC, Biermann K, Steyerberg EW, Kuipers EJ, Bruno MJ, et al. Nonsteroidal anti-inflammatory drugs and statins have chemopreventative effects in patients with Barrett's esophagus. Gastroenterology 2011;141:2000-8; quiz e13-4.

38 Beales IL, Vardi I, Dearman L. Regular statin and aspirin use in patients with Barrett's oesophagus is associated with a reduced incidence of oesophageal adenocarcinoma. Eur J Gastroenterol Hepatol 2012;24:917-23.

39 Aiman U, Najmi A, Khan RA. Statin induced diabetes and its clinical implications. J Pharmacol Pharmacother 2014;5:181-5.

40 Baker WL, Talati R, White CM, Coleman Cl. Differing effect of statins on insulin sensitivity in nondiabetics: a systematic review and meta-analysis. Diabetes Res Clin Pract 2010;87:98-107.

41 Jick $\mathrm{H}$, Jick SS, Derby LE. Validation of information recorded on general practitioner based computerised data resource in the United Kingdom. BMJ 1991;302:766-8.

42 Jick SS, Kaye JA, Vasilakis-Scaramozza C, Garcia Rodriguez LA, Ruigomez A, Meier CR, et al. Validity of the general practice research database. Pharmacotherapy 2003;23:686-9.

43 Reid FD, Cook DG, Whincup PH. Use of statins in the secondary prevention of coronary heart disease: is treatment equitable? Heart 2002;88:15-9.

44 Jick H, Jick S, Derby LE, Vasilakis C, Myers MW, Meier CR. Calcium-channel blockers and risk of cancer. Lancet 1997;349:525-8. 
Table 1. Characteristics of cases with biliary tract cancer and controls, CPRD ${ }^{\text {a }}$

\begin{tabular}{|c|c|c|c|}
\hline Characteristic & Case $(n=3,118)$ & Control $(n=15,519)$ & $P$ value \\
\hline Cancer site (n, \%) & & & -- \\
\hline Gallbladder & $708(22.7)$ & -- & \\
\hline Bile duct & $1678(53.8)$ & -- & \\
\hline Ampulla of Vater & $228(7.3)$ & -- & \\
\hline Mixed & $500(16.0)$ & -- & \\
\hline Missing & $4(0.1)$ & -- & \\
\hline \multicolumn{4}{|l|}{ Index year $(\mathrm{n}, \%)$} \\
\hline 1989-1999 & $369(11.8)$ & $1836(11.8)$ & -- \\
\hline $2000-2004$ & $633(20.3)$ & $3149(20.3)$ & \\
\hline $2005-2009$ & $884(28.4)$ & $4422(28.5)$ & \\
\hline $2010-2016$ & $1232(39.5)$ & $6112(39.4)$ & \\
\hline \multicolumn{4}{|c|}{ Years in CPRD prior to index date } \\
\hline Mean \pm SD & $22.4 \pm 17.0$ & $22.6 \pm 17.0$ & -- \\
\hline \multicolumn{4}{|c|}{ Age at index date, years (n, \%) } \\
\hline $20-49$ & $525(16.8)$ & $2607(16.8)$ & -- \\
\hline $50-69$ & $756(24.2)$ & $3822(24.6)$ & \\
\hline $70-79$ & $1010(32.4)$ & $5026(32.4)$ & \\
\hline $80-99$ & $827(26.5)$ & $4064(26.2)$ & \\
\hline Mean \pm SD & $71.0(11.9)$ & $71.0(11.8)$ & \\
\hline $\operatorname{Sex}(n, \%)$ & & & -- \\
\hline Male & $1439(46.2)$ & $7156(46.1)$ & -- \\
\hline Female & $1679(53.8)$ & $8363(53.9)$ & \\
\hline \multicolumn{4}{|c|}{ Body mass index, $\mathrm{kg} / \mathrm{m}^{2}(\mathrm{n}, \%)$} \\
\hline$<18.5$ (low) & $28(0.9)$ & $168(1.1)$ & $<0.001$ \\
\hline $18.5-24.9$ (normal) & $853(27.4)$ & $4788(30.9)$ & \\
\hline 25.0-29.9 (overweight) & $1102(35.3)$ & $5120(33.0)$ & \\
\hline $30.0+($ obese $)$ & $650(20.8)$ & $2577(16.6)$ & \\
\hline Missing/Unknown & $485(15.6)$ & $2866(18.5)$ & \\
\hline \multicolumn{4}{|l|}{ Smoking status (n, \%) } \\
\hline Never & $618(19.8)$ & $3472(22.4)$ & $<0.001$ \\
\hline Former & $1484(47.6)$ & $7340(47.3)$ & \\
\hline Current & $764(24.5)$ & $2964(19.1)$ & \\
\hline Missing/Unknown & $252(8.1)$ & $1743(11.2)$ & \\
\hline \multicolumn{4}{|c|}{ Alcohol drinking status (n, \%) } \\
\hline Never & $458(14.7)$ & $2339(15.1)$ & 0.002 \\
\hline Former & $131(4.2)$ & $548(3.5)$ & \\
\hline Current & $2022(64.8)$ & $9709(62.6)$ & \\
\hline
\end{tabular}


Missing/Unknown

\section{Chronic disease history (n, \%)}

Diabetes

Gallstone

Cirrhosis

Hepatitis virus infection

Cholecystectomy ${ }^{\mathrm{b}}$

Chronic heart disease

Dyslipidemia

Prescription drug use history (n, \%)

Treatment for Type 2 diabetes

Aspirin

Cortisone

Other lipid-lowering agents

Healthy user effect (n, \%)

High exercise

Healthy diet

\section{Healthy adherer effect (n, \%)}

Cancer screening

Influenza vaccination

Functional status or cognitive impairment (n, \%)

$$
507(16.3)
$$

$2923(18.8)$

$\begin{array}{rrr}15(0.5) & 11(0.1) & <0.001 \\ 29(0.9) & 34(0.2) & <0.001 \\ 234(7.5) & 480(3.1) & <0.001 \\ 127(5.3) & 546(4.5) & 0.138 \\ 677(21.7) & 3171(20.4) & 0.113 \\ 481(15.4) & 2540(16.4) & 0.203 \\ 458(14.7) & 1648(10.6) & <0.001\end{array}$

$330(10.6)$

$1070(34.3)$

$925(29.7)$

134 (4.3)

$26(0.8)$

$633(20.3)$

$672(21.6)$

$398(12.8)$

$\begin{array}{rr}1234(8.0) & <0.001 \\ 4927(31.7) & 0.002 \\ 4032(26.0) & <0.001 \\ 594(3.8) & 0.236\end{array}$

$186(1.2) \quad 0.097$ $2989(19.3) \quad 0.188$

Pneumonia

$101(3.2)$

$33(1.1)$

$155(5.0)$

Comorbidity

a Excludes 55 controls with entry date after exit date.

b Excludes 708 cases with gallbladder cancer and their 3,508 matched controls. 
Table 2. Association between statin use and biliary tract cancers, CPRD

\begin{tabular}{|c|c|c|c|}
\hline Characteristic & $\begin{array}{c}\text { Case } \\
(\mathrm{n}=\mathbf{3 , 1 1 8})\end{array}$ & $\begin{array}{c}\text { Control } \\
(\mathrm{n}=15,519)\end{array}$ & $\begin{array}{c}\text { Adjusted OR } \\
(95 \% \mathrm{CI}) \text { a }\end{array}$ \\
\hline \multicolumn{4}{|l|}{ Any statin use } \\
\hline Nonusers & $2159(69.2)$ & $10934(70.5)$ & ref. \\
\hline Ever & $959(30.8)$ & $4585(29.5)$ & $0.92(0.83,1.02)$ \\
\hline Former $^{b}$ & $199(6.4)$ & $831(5.4)$ & $1.10(0.92,1.31)$ \\
\hline Current & $760(24.4)$ & $3754(24.2)$ & $0.88(0.79,0.98)$ \\
\hline \multicolumn{4}{|c|}{$\begin{array}{l}\text { Time since first statin use } \\
\text { recorded (years) }\end{array}$} \\
\hline Nonusers & $2159(69.2)$ & $10934(70.5)$ & ref. \\
\hline $0-2$ & $206(6.6)$ & $1064(6.9)$ & $0.87(0.74,1.02)$ \\
\hline $3-5$ & $292(9.4)$ & $1316(8.5)$ & $0.98(0.84,1.13)$ \\
\hline $6-8$ & $233(7.5)$ & $1060(6.8)$ & $0.97(0.82,1.14)$ \\
\hline $9+$ & $228(7.3)$ & $1145(7.4)$ & $0.85(0.72,1.01)$ \\
\hline$P$ trend & & & 0.128 \\
\hline \multicolumn{4}{|c|}{ No. of prescriptions } \\
\hline Nonusers & $2159(69.2)$ & $10934(70.5)$ & ref. \\
\hline $2-15$ & $254(8.1)$ & $1169(7.5)$ & $0.98(0.84,1.14)$ \\
\hline $16-35$ & $236(7.6)$ & $1144(7.4)$ & $0.92(0.79,1.08)$ \\
\hline $36-65$ & $252(8.1)$ & $1089(7.0)$ & $1.00(0.85,1.17)$ \\
\hline $66+$ & $217(7.0)$ & $1183(7.6)$ & $0.76(0.64,0.91)$ \\
\hline$P$ trend & & & 0.016 \\
\hline \multicolumn{4}{|c|}{ Cumulative dose $^{c}$} \\
\hline Nonusers & $2159(69.2)$ & $10934(70.5)$ & ref. \\
\hline Q1 & $269(8.6)$ & $1146(7.4)$ & $1.07(0.93,1.24)$ \\
\hline Q2 & $225(7.2)$ & $1147(7.4)$ & $0.85(0.73,1.00)$ \\
\hline Q3 & $242(7.8)$ & $1147(7.4)$ & $0.90(0.77,1.06)$ \\
\hline Q4 & $223(7.2)$ & $1144(7.4)$ & $0.81(0.68,0.96)$ \\
\hline Missing & 0 & 1 & \\
\hline$P$ trend & & & 0.008 \\
\hline
\end{tabular}

Abbreviation: CI, confidence interval; Q, quartile; OR, odds ratios

a Adjusted for body mass index, smoking, alcohol drinking, and diabetes

b Former: Stopped using statins 1+ years before index date

c Q1=13175, Q2=32480, Q3 $=65520$ 
Table 3. Association between statin use and subsites of biliary tract cancer, CPRD ${ }^{\text {a }}$

\begin{tabular}{|c|c|c|c|c|c|c|c|c|c|}
\hline \multirow[b]{2}{*}{ Characteristic } & \multicolumn{3}{|c|}{ Gallbladder $^{\text {b }}$} & \multicolumn{3}{|c|}{ Bile duct ${ }^{c}$} & \multicolumn{3}{|c|}{ Ampulla of Vater } \\
\hline & $\begin{array}{c}\text { Case } \\
(n=708)\end{array}$ & $\begin{array}{c}\text { Control } \\
(\mathrm{n}=3331)\end{array}$ & $\begin{array}{l}\text { Adjusted OR } \\
\text { (95\% CI) }\end{array}$ & $\begin{array}{c}\text { Case } \\
(\mathrm{n}=1678)\end{array}$ & $\begin{array}{c}\text { Control } \\
(\mathrm{n}=8322)\end{array}$ & $\begin{array}{c}\text { Adjusted OR } \\
\text { (95\% CI) }\end{array}$ & $\begin{array}{c}\text { Case } \\
(n=228)\end{array}$ & $\begin{array}{c}\text { Control } \\
(\mathrm{n}=1125)\end{array}$ & $\begin{array}{c}\text { Adjusted OR } \\
(95 \% \text { CI) a }\end{array}$ \\
\hline \multicolumn{10}{|l|}{ Any statin use } \\
\hline Nonusers & 495 (69.9) & $2374(71.3)$ & ref. & $1167(69.5)$ & $5880(70.7)$ & ref. & $162(71.1)$ & $802(71.3)$ & ref. \\
\hline Ever & $213(30.1)$ & 957 (28.7) & $0.89(0.71,1.11)$ & $511(30.5)$ & $2442(29.3)$ & $0.92(0.80,1.05)$ & $66(28.9)$ & $323(28.7)$ & $0.96(0.66,1.41)$ \\
\hline Former & $49(6.9)$ & $198(5.9)$ & $1.01(0.69,1.48)$ & $106(6.3)$ & $426(5.1)$ & $1.14(0.89,1.45)$ & $17(7.5)$ & $65(5.8)$ & $1.30(0.68,2.46)$ \\
\hline Current & $164(23.2)$ & $759(22.8)$ & $0.86(0.67,1.09)$ & $405(24.1)$ & $2016(24.2)$ & $0.87(0.75,1.01)$ & $49(21.5)$ & $258(22.9)$ & $0.89(0.59,1.34)$ \\
\hline \multicolumn{10}{|l|}{$\begin{array}{l}\text { Time since first } \\
\text { statin use recorded } \\
\text { (years) }\end{array}$} \\
\hline Nonusers & 495 (69.9) & $2374(71.3)$ & ref. & $1167(69.5)$ & $5880(70.7)$ & ref. & $162(71.1)$ & $802(71.3)$ & ref. \\
\hline $0-2$ & $41(5.8)$ & $195(5.9)$ & $0.84(0.57,1.24)$ & $110(6.6)$ & $572(6.9)$ & $0.82(0.66,1.04)$ & $14(6.1)$ & $82(7.3)$ & $0.74(0.39,1.41)$ \\
\hline $3-5$ & $63(8.9)$ & $297(8.9)$ & $0.85(0.61,1.19)$ & $160(9.5)$ & $691(8.3)$ & $1.02(0.84,1.25)$ & $15(6.6)$ & $81(7.2)$ & $0.88(0.47,1.63)$ \\
\hline $6-8$ & $60(8.5)$ & $228(6.8)$ & $1.08(0.76,1.54)$ & $125(7.4)$ & $569(6.8)$ & $0.97(0.78,1.22)$ & $14(6.1)$ & $82(7.3)$ & $0.86(0.45,1.65)$ \\
\hline $9+$ & $49(6.9)$ & $237(7.1)$ & $0.79(0.54,1.17)$ & $116(6.9)$ & $610(7.3)$ & $0.82(0.65,1.05)$ & $23(10.1)$ & $78(6.9)$ & $1.68(0.89,3.15)$ \\
\hline$P$ trend & & & 0.391 & & & 0.246 & & & 0.433 \\
\hline \multicolumn{10}{|l|}{ No. of prescriptions } \\
\hline Nonusers & $495(69.9)$ & $2374(71.3)$ & ref. & $1167(69.5)$ & $5880(70.7)$ & ref. & $162(71.1)$ & $802(71.3)$ & ref. \\
\hline $2-15$ & $54(7.6)$ & $227(6.8)$ & $0.98(0.69,1.39)$ & $136(8.1)$ & $642(7.7)$ & $0.93(0.76,1.15)$ & $19(8.3)$ & $83(7.4)$ & $1.02(0.58,1.81)$ \\
\hline $16-35$ & $47(6.6)$ & $248(7.4)$ & $0.76(0.53,1.09)$ & $133(7.9)$ & $608(7.3)$ & $0.97(0.79,1.20)$ & $18(7.9)$ & $71(6.3)$ & $1.20(0.66,2.15)$ \\
\hline $36-65$ & $60(8.5)$ & $242(7.3)$ & $0.97(0.69,1.36)$ & $136(8.1)$ & $568(6.8)$ & $1.04(0.83,1.29)$ & $14(6.1)$ & $81(7.2)$ & $0.80(0.42,1.54)$ \\
\hline $66+$ & $52(7.3)$ & $240(7.2)$ & $0.84(0.58,1.24)$ & $106(6.3)$ & $624(7.5)$ & $0.71(0.55,0.90)$ & $15(6.6)$ & $88(7.8)$ & $0.77(0.39,1.50)$ \\
\hline$P$ trend & & & 0.306 & & & 0.063 & & & 0.498 \\
\hline \multicolumn{10}{|l|}{ Cumulative dose ${ }^{d}$} \\
\hline Nonusers & 495 (69.9) & $2374(71.3)$ & ref. & $1167(69.5)$ & $5880(70.7)$ & ref. & $162(71.1)$ & $802(71.3)$ & ref. \\
\hline Q1 & $62(8.8)$ & $240(7.2)$ & $1.08(0.78,1.49)$ & $145(8.6)$ & $635(7.6)$ & $1.02(0.83,1.25)$ & $15(6.6)$ & $77(6.8)$ & $0.92(0.51,1.65)$ \\
\hline Q2 & $52(7.3)$ & $239(7.2)$ & $0.88(0.62,1.25)$ & $114(6.8)$ & $598(7.2)$ & $0.83(0.66,1.04)$ & $22(9.6)$ & $81(7.2)$ & $1.30(0.74,2.31)$ \\
\hline Q3 & $44(6.2)$ & $239(7.2)$ & $0.66(0.45,0.97)$ & $139(8.3)$ & $601(7.2)$ & $1.00(0.81,1.24)$ & $10(4.4)$ & $82(7.3)$ & $0.67(0.33,1.36)$ \\
\hline
\end{tabular}




\begin{tabular}{|c|c|c|c|c|c|c|c|c|c|}
\hline Q4 & $55(7.8)$ & $238(7.1)$ & $0.91(0.62,1.32)$ & $113(6.7)$ & $608(7.3)$ & $0.79(0.62,1.00)$ & $19(8.3)$ & $83(7.4)$ & $0.97(0.51,1.85)$ \\
\hline$P$ trend & & & 0.141 & & & 0.081 & & & 0.739 \\
\hline
\end{tabular}

Abbreviation: $\mathrm{CI}$, confidence interval; Q, quartile; OR, odds ratio

a ORs are adjusted for body mass index, smoking, alcohol drinking, and diabetes.

b ORs are additionally adjusted for gallstones. Excludes 177 controls with a history of cholecystectomy.

c ORs are additionally adjusted for cirrhosis.

d For gallbladder cancer, Q1 $=14560, \mathrm{Q} 2=34720, \mathrm{Q} 3=66080$; for cancer in Bile duct, $\mathrm{Q} 1=13440, \mathrm{Q} 2=32480, \mathrm{Q} 3=66080$; for cancer of Ampulla of Vater, $\mathrm{Q} 1=12320, \mathrm{Q} 2=33600$, $\mathrm{Q} 3=63840$. 


\section{Supplementary Materials}

Identification of indicators of healthy user effect, healthy adherer effect, and functional status

We assessed healthy user effect, healthy adherer effect, and functional status prior to the index date because these factors have been suggested as important confounders in observational studies.[1] We used high exercise (i.e., Readcodes for active/intermediate/heavy exercise or exercises $\geq 1$ time per work) and healthy diet (i.e., Readcodes for healthy diet, vegetarian diet, low cholesterol diet, gluten free diet, high fiber diet, low fat diet, or low salt diet) as indications of healthy users, participation in cancer screening and influenza vaccination as indications of healthy adherers, and pneumonia, dementia, and certain comorbidities (i.e., organ failure including respiratory system, heart, liver, and kidney) as indications of functional status.

\section{Reference}

1 Shrank WH, Patrick AR, Brookhart MA. Healthy user and related biases in observational studies of preventive interventions: a primer for physicians. J Gen Intern Med 2011;26:546-50. 
Supplementary Table 1. Read codes used to identify biliary tract cancers, CPRD

\begin{tabular}{|c|c|c|c|}
\hline Cancer site & medcode & readcode & readterm \\
\hline \multicolumn{4}{|c|}{ Gallbladder cancer } \\
\hline & 16105 & B160.00 & Malignant neoplasm of gallbladder \\
\hline & 31393 & B160.11 & Carcinoma gallbladder \\
\hline & 46594 & B808300 & Carcinoma in situ of gall bladder \\
\hline \multicolumn{4}{|c|}{ Cholangiocarcinoma } \\
\hline & 8711 & BB5D100 & {$[\mathrm{M}]$ Cholangiocarcinoma } \\
\hline & 40438 & BB5D111 & [M]Bile duct carcinoma \\
\hline & 41313 & BB5D300 & [M]Bile duct cystadenocarcinoma \\
\hline & 110775 & B151100 & Malignant neoplasm of interlobular biliary canals \\
\hline & 89593 & B151200 & Malignant neoplasm of intrahepatic biliary passages \\
\hline & 16915 & B151.00 & Malignant neoplasm of intrahepatic bile ducts \\
\hline & 61643 & $\mathrm{~B} 151 \mathrm{z} 00$ & Malignant neoplasm of intrahepatic bile ducts NOS \\
\hline & 99580 & B808100 & Carcinoma in situ of intrahepatic bile ducts \\
\hline & 58088 & B151400 & Malignant neoplasm of intrahepatic gall duct \\
\hline & 65124 & B151000 & Malignant neoplasm of interlobular bile ducts \\
\hline & 23433 & B161.00 & Malignant neoplasm of extrahepatic bile ducts \\
\hline & 74896 & $\mathrm{~B} 161 \mathrm{z} 00$ & Malignant neoplasm of extrahepatic bile ducts NOS \\
\hline & 36495 & B161211 & Carcinoma common bile duct \\
\hline & 7982 & B161200 & Malignant neoplasm of common bile duct \\
\hline & 52537 & B161100 & Malignant neoplasm of hepatic duct \\
\hline & 37501 & B808200 & Carcinoma in situ of hepatic duct \\
\hline & 64089 & B808500 & Carcinoma in situ of common bile duct \\
\hline & 72445 & B161000 & Malignant neoplasm of cystic duct \\
\hline \multicolumn{4}{|c|}{ Ampulla of Vater cancer } \\
\hline & 10949 & B162.00 & Malignant neoplasm of ampulla of Vater \\
\hline & 21792 & B808600 & Carcinoma in situ of ampulla of Vater \\
\hline & 105613 & B161300 & Malignant neoplasm of sphincter of Oddi \\
\hline \multicolumn{4}{|l|}{ Mixed } \\
\hline & 54103 & B16.00 & Malignant neoplasm gallbladder and extrahepatic bile ducts \\
\hline & 15907 & B16z.00 & Malignant neoplasm gallbladder/extrahepatic bile ducts NOS \\
\hline & 60312 & B16y.00 & Malignant neoplasm other gallbladder/extrahepatic bile duct \\
\hline & 38978 & B15z.00 & Malignant neoplasm of liver and intrahepatic bile ducts NOS \\
\hline & 8918 & B15..00 & Malignant neoplasm of liver and intrahepatic bile ducts \\
\hline & 35039 & B163.00 & Malignant neoplasm, overlapping lesion of biliary tract \\
\hline & 54103 & B16..00 & Malignant neoplasm gallbladder and extrahepatic bile ducts \\
\hline & 70516 & BB5D.11 & {$[\mathrm{M}]$ Biliary tract adenomas and adenocarcinomas } \\
\hline & 107299 & BB5D700 & [M]Combined hepatocellular carcinoma and cholangiocarcinoma \\
\hline & 110147 & BB5D711 & {$[\mathrm{M}]$ Hepatocholangiocarcinoma } \\
\hline & 36031 & BB5D.00 & [M]Hepatobiliary tract adenomas and carcinomas \\
\hline
\end{tabular}


66673 B808.00 Carcinoma in situ of liver and biliary system

51934 B808.11 Carcinoma in situ of biliary system

$98540 \quad$ B808z00 Carcinoma in situ of liver or biliary system NOS 
Supplementary Table 2. Association between statin use and biliary tract cancers, CPRD

\begin{tabular}{|c|c|c|c|c|}
\hline Characteristic & $\begin{array}{c}\text { Case } \\
(\mathrm{n}=\mathbf{3 , 1 1 8})\end{array}$ & $\begin{array}{c}\text { Control } \\
(\mathrm{n}=15,519)\end{array}$ & $\begin{array}{c}\text { Stepwise selection } \\
\text { Adjusted OR } \\
(95 \% \text { CI })^{a} \\
\end{array}$ & $\begin{array}{c}\text { Fully } \\
\text { Adjusted OR } \\
(95 \% \text { CI) } \\
\end{array}$ \\
\hline \multicolumn{5}{|l|}{ Any statin use } \\
\hline Nonusers & $2159(69.2)$ & $10934(70.5)$ & ref. & ref. \\
\hline Ever & $959(30.8)$ & $4585(29.5)$ & $0.92(0.81,1.03)$ & $0.91(0.81,1.03)$ \\
\hline Former $^{\mathrm{c}}$ & $199(6.4)$ & $831(5.4)$ & $1.07(0.89,1.29)$ & $1.06(0.88,1.29)$ \\
\hline Current & $760(24.4)$ & $3754(24.2)$ & $0.88(0.78,1.00)$ & $0.88(0.78,1.00)$ \\
\hline \multicolumn{5}{|c|}{$\begin{array}{l}\text { Time since statin } \\
\text { use firstly recorded } \\
\text { (years) }\end{array}$} \\
\hline Nonusers & $2159(69.2)$ & $10934(70.5)$ & ref. & ref. \\
\hline $0-2$ & $206(6.6)$ & $1064(6.9)$ & $0.86(0.72,1.02)$ & $0.85(0.72,1.02)$ \\
\hline $3-5$ & $292(9.4)$ & $1316(8.5)$ & $0.97(0.83,1.14)$ & $0.96(0.82,1.13)$ \\
\hline $6-8$ & $233(7.5)$ & $1060(6.8)$ & $0.97(0.81,1.16)$ & $0.96(0.80,1.15)$ \\
\hline $9+$ & $228(7.3)$ & $1145(7.4)$ & $0.87(0.71,1.05)$ & $0.86(0.70,1.04)$ \\
\hline$P$ trend & & & 0.266 & 0.232 \\
\hline \multicolumn{5}{|c|}{ No. of prescriptions } \\
\hline Nonusers & $2159(69.2)$ & $10934(70.5)$ & ref. & ref. \\
\hline $2-15$ & $254(8.1)$ & $1169(7.5)$ & $0.95(0.81,1.12)$ & $0.94(0.80,1.11)$ \\
\hline $16-35$ & $236(7.6)$ & $1144(7.4)$ & $0.91(0.77,1.08)$ & $0.90(0.76,1.07)$ \\
\hline $36-65$ & $252(8.1)$ & $1089(7.0)$ & $0.99(0.83,1.18)$ & $0.98(0.82,1.17)$ \\
\hline $66+$ & $217(7.0)$ & $1183(7.6)$ & $0.78(0.64,0.95)$ & $0.77(0.64,0.94)$ \\
\hline$P$ trend & & & 0.048 & 0.043 \\
\hline \multicolumn{5}{|c|}{ Cumulative dose ${ }^{d}$} \\
\hline Nonusers & $2159(69.2)$ & $10934(70.5)$ & ref. & ref. \\
\hline Q1 & $269(8.6)$ & $1146(7.4)$ & $1.05(0.89,1.23)$ & $1.04(0.88,1.22)$ \\
\hline Q2 & $225(7.2)$ & $1147(7.4)$ & $0.85(0.71,1.01)$ & $0.84(0.71,1.01)$ \\
\hline Q3 & $242(7.8)$ & $1147(7.4)$ & $0.89(0.75,1.06)$ & $0.89(0.75,1.06)$ \\
\hline Q4 & $223(7.2)$ & $1144(7.4)$ & $0.82(0.67,0.99)$ & $0.81(0.67,0.98)$ \\
\hline Missing & 0 & 1 & & \\
\hline$P$ trend & & & 0.017 & 0.015 \\
\hline
\end{tabular}

Abbreviation: CI, confidence interval; Q, quartile; OR, odds ratios

a Adjusted for BMI, smoking, alcohol drinking, hepatitis virus infection, cirrhosis, gallstone, dyslipidemia, diabetes, Aspirin, cortisone, high exercise, and dementia.

b Adjusted for BMI, smoking, alcohol drinking, hepatitis virus infection, cirrhosis, gallstone, chronic heart disease, dyslipidemia, diabetes, Aspirin, cortisone, other lipid regulation drug, high exercise, health diet, pneumonia, cancer screening, influenza vaccination, dementia, and comorbidity.

c Former: Stopped using statins 1+ years before index date

$\mathrm{d}$ Q1=13175, Q2=32480, Q3=65520 
Supplementary Table 3. Association between statin use and biliary tract cancers overall and by subtype, CPRD ${ }^{\text {a }}$

\begin{tabular}{|c|c|c|c|c|c|c|c|c|c|c|c|c|}
\hline \multirow[b]{2}{*}{ Characteristic } & \multicolumn{3}{|c|}{ Biliary tract cancers overall } & \multicolumn{3}{|c|}{ Gallbladder $^{\mathrm{b}}$} & \multicolumn{3}{|c|}{ Bile duct } & \multicolumn{3}{|c|}{ Ampulla of Vater } \\
\hline & $\begin{array}{c}\text { Case } \\
(\mathbf{n}=\mathbf{3 , 1 1 8})\end{array}$ & $\begin{array}{c}\text { Control } \\
(n=15,519)\end{array}$ & $\begin{array}{c}\text { Adjusted OR } \\
\text { (95\% CI) }\end{array}$ & $\begin{array}{c}\text { Case } \\
(\mathrm{n}=708)\end{array}$ & $\begin{array}{c}\text { Control } \\
(\mathrm{n}=3331)\end{array}$ & $\begin{array}{c}\text { Adjusted OR } \\
\text { (95\% CI) }\end{array}$ & $\begin{array}{c}\text { Case } \\
(n=1678)\end{array}$ & $\begin{array}{c}\text { Control } \\
(\mathrm{n}=8322)\end{array}$ & $\begin{array}{c}\text { Adjusted OR } \\
\text { (95\% CI) }\end{array}$ & $\begin{array}{c}\text { Case } \\
(\mathrm{n}=228)\end{array}$ & $\begin{array}{c}\text { Control } \\
(n=1125)\end{array}$ & $\begin{array}{c}\text { Adjusted OR } \\
\text { (95\% CI) }\end{array}$ \\
\hline \multicolumn{13}{|l|}{ Type of statin } \\
\hline Nonusers & $2159(69.2)$ & $10934(70.5)$ & ref. & $171(24.2)$ & $763(22.9)$ & ref. & $408(24.3)$ & $1988(23.9)$ & ref. & $162(71.1)$ & $802(71.3)$ & ref. \\
\hline Simvastatin & $764(24.5)$ & $3696(23.8)$ & $0.92(0.83,1.02)$ & 77 (10.9) & $384(11.5)$ & $0.89(0.70,1.12)$ & $195(11.6)$ & $930(11.2)$ & $0.91(0.79,1.04)$ & $52(22.8)$ & $258(22.9)$ & $0.93(0.63,1.39)$ \\
\hline Atorvastatin & $361(11.6)$ & $1789(11.5)$ & $0.88(0.78,1.01)$ & $25(3.5)$ & $100(3.0)$ & $0.84(0.63,1.12)$ & $57(3.4)$ & $321(3.9)$ & $0.94(0.79,1.13)$ & $29(12.7)$ & $126(11.2)$ & $1.15(0.70,1.87)$ \\
\hline Pravastatin & $111(3.6)$ & $553(3.6)$ & $0.91(0.74,1.13)$ & $16(2.3)$ & $59(1.8)$ & $1.01(0.62,1.65)$ & $27(1.6)$ & $139(1.7)$ & $0.81(0.60,1.10)$ & $10(4.4)$ & $33(2.9)$ & $1.64(0.76,3.54)$ \\
\hline Rosuvastatin & $57(1.8)$ & $260(1.7)$ & $0.98(0.72,1.33)$ & $2(0.3)$ & $25(0.8)$ & $1.08(0.57,2.02)$ & $13(0.8)$ & $69(0.8)$ & $0.87(0.57,1.33)$ & $6(2.6)$ & $17(1.5)$ & $1.73(0.65,4.60)$ \\
\hline
\end{tabular}

Abbreviation: $\mathrm{CI}$, confidence interval; $\mathrm{OR}$, odds ratios

a Adjusted for body mass index, smoking, alcohol drinking, and diabetes.

b Odds ratios are additionally adjusted for gallstones. Excludes 177 controls with a history of cholecystectomy. 


\begin{tabular}{|c|c|c|c|c|c|c|c|c|c|c|c|c|c|c|c|}
\hline \multirow{3}{*}{ Characteristic } & \multicolumn{5}{|c|}{ Sex } & \multicolumn{5}{|c|}{ Age at index date (years) } & \multicolumn{5}{|c|}{ Index year } \\
\hline & \multicolumn{2}{|c|}{ Male } & \multicolumn{2}{|c|}{ Female } & \multirow[t]{2}{*}{$\begin{array}{c}P \\
\text { heterogeneity } \\
\end{array}$} & \multicolumn{2}{|c|}{$\leq 70$} & \multicolumn{2}{|c|}{$>70$} & \multirow[t]{2}{*}{$\begin{array}{c}P \\
\text { heterogeneity }\end{array}$} & \multicolumn{2}{|c|}{$\leq 2004$} & \multicolumn{2}{|c|}{$>2004$} & \multirow[t]{2}{*}{$\begin{array}{c}P \\
\text { heterogeneity }\end{array}$} \\
\hline & $\begin{array}{c}\text { No. of } \\
\text { cases/controls }\end{array}$ & 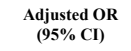 & $\begin{array}{c}\text { No. of } \\
\text { cases/controls }\end{array}$ & $\begin{array}{c}\text { Adjusted OR } \\
(95 \% \mathrm{CI})\end{array}$ & & $\begin{array}{c}\text { No. of } \\
\text { casesc ontrols }\end{array}$ & 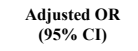 & $\begin{array}{c}\text { No. of } \\
\text { cases/controls }\end{array}$ & 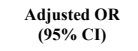 & & $\begin{array}{c}\text { No. of } \\
\text { cases/controls }\end{array}$ & $\begin{array}{c}\text { Adjusted OR } \\
(95 \% \text { Cl) }\end{array}$ & $\begin{array}{c}\text { No. of } \\
\text { cases/controls }\end{array}$ & 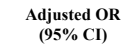 & \\
\hline Any statin use & & & & & 0.3 & & & & & 0.345 & & & & & 0.953 \\
\hline Nonusers & 92944790 & ref. & $1230 / 6144$ & ref. & & $1085 / 5475$ & ref. & 1074/5459 & ref. & & $907 / 4521$ & ref. & 1252/6413 & ref. & \\
\hline Former & $98 / 364$ & $1.34(1.03,1.74)$ & $101 / 466$ & $0.94(0.74,1.20)$ & & $53 / 229$ & $1.03(0.74,1.42)$ & 146/601 & $1.13(0.91,1.40)$ & & $10 / 57$ & $0.79(0.39,1.59)$ & $189 / 773$ & $1.14(0.94,1.37)$ & \\
\hline Current & 412/2002 & $0.94(0.81,1.09)$ & $348 / 1752$ & $0.83(0.71,0.97)$ & & $254 / 1285$ & $0.85(0.71,1.01)$ & $506 / 2469$ & $0.90(0.79,1.03)$ & & $85 / 406$ & $0.86(0.66,1.12)$ & $675 / 3348$ & $0.89(0.79,1.00)$ & \\
\hline $\begin{array}{l}\text { No. of } \\
\text { prescriptions }\end{array}$ & & & & & 0.273 & & & & & 0.463 & & & & & 0.997 \\
\hline Nonusers & 92947790 & ref. & 1230/6144 & ref. & & $1085 / 5475$ & ref. & 1074/5459 & ref. & & $907 / 4521$ & ref. & $1252 / 6413$ & ref. & \\
\hline $2-15$ & 134/581 & $1.09(0.88,1.35)$ & 120/587 & $0.87(0.70,1.08)$ & & 91/469 & $0.85(0.67,1.09)$ & 163/699 & $1.07(0.88,1.30)$ & & 47/227 & $0.86(0.61,1.21)$ & $207 / 941$ & $1.00(0.84,1.19)$ & \\
\hline $16-35$ & $117 / 571$ & $0.95(0.76,1.20)$ & $119 / 573$ & $0.89(0.71,1.11)$ & & 92/432 & $0.95(0.74,1.22)$ & 144/712 & $0.90(0.74,1.11)$ & & $26 / 139$ & $0.79(0.51,1.23)$ & $210 / 1005$ & $0.94(0.79,1.12)$ & \\
\hline $36-65$ & 139/594 & $1.06(0.85,1.32)$ & $113 / 495$ & $0.94(0.75,1.19)$ & & $76 / 344$ & $0.92(0.70,1.22)$ & $176 / 745$ & $1.03(0.85,1.26)$ & & $16 / 73$ & $0.87(0.49,1.52)$ & $236 / 1016$ & $1.02(0.86,1.20)$ & \\
\hline $66+$ & 120/620 & $0.85(0.67,1.08)$ & $97 / 563$ & $0.69(0.53,0.88)$ & & 48269 & $0.73(0.52,1.04)$ & 169/914 & $0.78(0.63,0.95)$ & & $6 / 24$ & $1.08(0.43,2.71)$ & $211 / 1159$ & $0.77(0.65,0.92)$ & \\
\hline$P$ trend & & 0.433 & & 0.012 & & & 0.112 & & 0.065 & & & 0.339 & & 0.039 & \\
\hline $\begin{array}{l}\text { Cumulative } \\
\text { dose }\end{array}$ & & & & & 0.366 & & & & & 0.566 & & & & & 0.577 \\
\hline Nonusers & 929/4790 & ref. & 1230/6144 & ref. & & $1085 / 5475$ & ref. & 1074/5459 & ref. & & $907 / 4521$ & ref. & $1252 / 6413$ & ref. & \\
\hline Q1 & $133 / 553$ & $1.15(0.93,1.43)$ & 136/593 & $1.00(0.81,1.23)$ & & $90 / 420$ & $0.98(0.76,1.25)$ & 179/726 & $1.13(0.94,1.36)$ & & $61 / 279$ & $0.93(0.69,1.26)$ & 208/867 & $1.11(0.94,1.32)$ & \\
\hline Q2 & $123 / 576$ & $0.97(0.78,1.22)$ & $102 / 571$ & $0.75(0.59,0.95)$ & & 78401 & $0.83(0.63,1.08)$ & $147 / 746$ & $0.87(0.71,1.07)$ & & $25 / 131$ & $0.75(0.48,1.18)$ & $200 / 1016$ & $0.87(0.73,1.04)$ & \\
\hline Q3 & $136 / 622$ & $0.98(0.78,1.22)$ & $106 / 525$ & $0.83(0.66,1.05)$ & & $73 / 382$ & $0.81(0.61,1.08)$ & $169 / 765$ & $0.95(0.78,1.16)$ & & $7 / 47$ & $0.65(0.29,1.46)$ & $235 / 1100$ & $0.93(0.79,1.10)$ & \\
\hline Q4 & $118 / 615$ & $0.84(0.66,1.07)$ & $105 / 529$ & $0.79(0.62,1.02)$ & & $66 / 311$ & $0.86(0.63,1.17)$ & $157 / 833$ & $0.79(0.64,0.98)$ & & $2 / 6$ & $1.22(0.24,6.21)$ & $221 / 1138$ & $0.83(0.69,0.99)$ & \\
\hline$P$ trend & & 0.188 & & 0.976 & & & 0.841 & & 0.193 & & & 0.634 & & 0.218 & \\
\hline
\end{tabular}

Abbreviation: $\mathrm{Cl}$, confidence interval; $\mathrm{OR}$, odds ratios

a Adjusted for body mass index smoking, alcohol drinking, and diabetes 